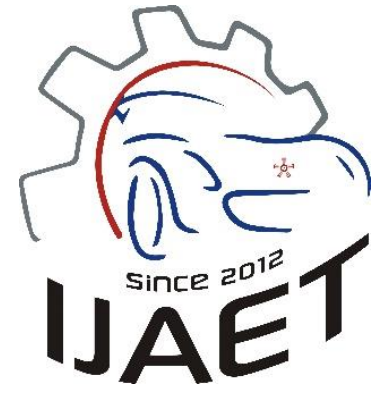

e-ISSN: 2146 - 9067

International Journal of Automotive

Engineering and Technologies

journal homepage:

https://dergipark.org.tr/en/pub/ijaet

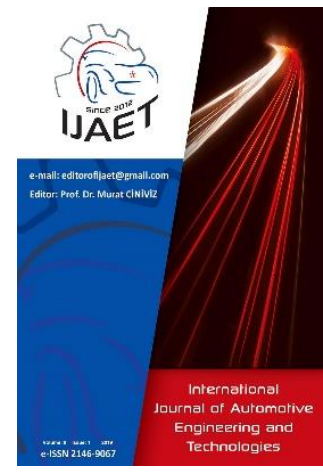

\title{
Original Research Article \\ Determination of effects of compression ratio variation on performance and emission characteristics of a diesel engine fueled with EDTA-doped sunflower biodiesel-petrodiesel
}

\author{
Ali Can Y1lmaz ${ }^{1 *}$ \\ ${ }^{1}$ Cukurova University, Adana Vocational School of Higher Education, Department of Motor Vehicles and Transportation \\ Technologies, 01330, Adana, Turkey
}

\section{ARTICLE INFO}

* Corresponding author acyilmaz@cu.edu.tr

Received: July 17, 2019

Accepted: Oct 21, 2019

Published by Editorial Board Members of IJAET

(C) This article is distributed by Turk Journal Park System under the CC 4.0 terms and conditions.

\begin{abstract}
This experimental study focuses on unraveling the effects of compression ratio (CR) variation on performance and emission characteristics of a variable compression ratio (VCR) diesel engine under various loads. The engine was fueled with $100 \%$ sunflower biodiesel (B100) and B100 with Ethylenediaminetetraacetic acid (EDTA, $\mathrm{C}_{10} \mathrm{H}_{16} \mathrm{~N}_{2} \mathrm{O}_{8}$ ) additive (B100+EDTA), separately, to determine fuel effect. Subsequent to determination of fuel properties, effects of these two fuels were compared under 3 different CRs. High hydrogen and oxygen contents, negligible chemical inactivity and high cetane number $(\mathrm{CN})$ made EDTA an attractive additive for B100 in the context of engine characteristics. It was observed that, B100+EDTA depicted higher average $\eta_{t}$ values of $24.3 \%, 25.7 \%$ and $26.5 \%$ whereas they were $17.3 \%, 18.7 \%$ and $19.4 \%$ for $\mathrm{B} 100$ under CRs of 16,17 and 18 , respectively. In terms of BSFC, average B100 values were 17.3, 16.1, 14.8 $(\mathrm{kJ} / \mathrm{kWh})$ whereas $10.1,9.2,7.9(\mathrm{~kJ} / \mathrm{kWh})$ for B100+EDTA under CRs of 16 , 17 and 18 , respectively. $\mathrm{T}_{\mathrm{e}}$ values were $265^{\circ} \mathrm{C}, 252^{\circ} \mathrm{C}$ and $234^{\circ} \mathrm{C}$ for B100+EDTA and $296^{\circ} \mathrm{C}, 281^{\circ} \mathrm{C}$ and $267^{\circ} \mathrm{C}$ for B100 at CRs of 16,17 and 18 , respectively. $\mathrm{CO}$ values were 110, 103 and 96 (ppm) for B100; 82, 74 and 65 (ppm) for B100+EDTA under under in-question CRs. UHC values of 124, 115 and $98(\mathrm{ppm})$ for B100+EDTA; 141, 134 and 119 (ppm) for B100 were obtained under CRs of 16, 17 and 18, respectively. $\mathrm{CO}_{2}$ emission values were $4.2 \%, 5.7 \%$ and $6.3 \%$ (by vol.) for B100+EDTA; $3.4 \%, 3.9 \%$ and $5.1 \%$ for B100 under CRs of 16, 17 and 18, respectively. $\mathrm{NO}_{\mathrm{x}}$ values were 170,192 and 210 (ppm) for B100+EDTA; 104, 126 and 137 (ppm) for B100 under CRs of 16,17 and 18 respectively. Smoke opacity values were $16 \%, 12 \%$ and $10 \%$ for B100+EDTA; $21 \%, 18 \%$ and $16 \%$ for B100 under CRs of 16, 17 and 18, respectively.

Keywords: Biodiesel, EDTA, variable compression ratio, diesel engine
\end{abstract}

\section{Introduction}

Environmental impacts and rapid depletion of fossil fuels have directed researchers to investigation of bio fuels from bio renewable resources [1, 2]. Vegetable oils, animal fats and their derivatives are of great interest for diesel engines due to recent increments in petroleum prices [3]. Bio fuels derived from vegetable oils 
have peculiar importance in terms of renewability and being cleaner energy source compared to petro-diesel fuel for diesel engine $[4,5]$. Substitution of bio fuels obtained from vegetable oil for petro-diesel is related to various ways: (i) crude oil; (ii) bio fuel-diesel fuel blend with appropriate fractions and (iii) trans-esterification process $[5,6]$. Vegetable oils may be produced from various seed crops that can be cultivated anywhere, they have comparable energy content with petro-diesel and lower exhaust emissions and high lubricity in general [7]. On the other hand, high viscosity value of bio diesel fuel causes challenges in fuel pumping [8].

There have been several studies on effects of various chemical additives into diesel fuel or biodiesel in order to investigate performance and emission characteristics of diesel engines. Beck, et al. [9] conducted an investigation of the effect of detergent-dispersant additives on the oxidation stability of biodiesel, diesel fuel and their blends. They blended commercial biodiesels produced from rapeseed oil and used cooking oil to diesel fuel in 5\%, 7\%, and $10 \%$ mass fractions. They concluded that, during the thermal oxidation of fatty acid, methyl esters decomposed to carbonyl, carboxyl and hydroxyl compounds, while cis-trans isomerization also occurred. Imtenan, et al. [10] investigated the impact of oxygenated additives to palm and jatropha biodiesel blends in the context of performance and emissions characteristics of a light-duty diesel engine. They made a blend which consists of $80 \%$ diesel, $15 \%$ biodiesel, and $5 \%$ oxygenated additive. It was observed that, improved performance values were achieved while reduced emission values were obtained except HC. Ileri and Kocar [11] conducted an experimental investigation of the effect of antioxidant additives on $\mathrm{NO}_{\mathrm{x}}$ emissions of a diesel engine using biodiesel. They dissolved butylatedhydroxyanisole (BHA), butylatedhydroxytoluene (BHT), tertbutylhydroquinone (TBHQ) and 2-ethylhexyl nitrate $(\mathrm{EHN})$ at concentrations of $0,500,750$ and 1000 ppm by weight in B20 fuel blend for experiments. The results showed that, antioxidant additives have quite effects on oxides of nitrogen $\left(\mathrm{NO}_{x}\right)$, carbon monoxide (CO) and hydrocarbon (HC) emissions of diesel engine running on biodiesel. A 1000 ppm concentration of EHN additive was optimal as $\mathrm{NO}_{x}$ levels were substantially reduced in the whole engine speed in comparison to B20 fuel. Caynak et al. [12] investigated on improvement of biodiesel produced from pomace oil and its properties with synthetic manganese additive. They blended organic based manganese additive and observed improvements in biodiesel properties in terms of viscosity, pour point and flash point. Karavalakis et al. [13] examined the factors influencing the stability of several biodiesel blends with low and ultra-low sulphur automotive diesel fuels and they aimed to evaluate the impact of biodiesel source material and biodiesel concentration in diesel fuel, on the stability of the final blend. Tracy et al. [14] hydrogenated myrcene and limonene to their fully saturated forms 2,6-dimethyloctane and 1isopropyl-4-methylcyclohexane, respectively as fuel additives. The results demonstrated that all tested mixtures were within the acceptable ranges specified by ASTM for diesel fuel and that the additives lowered the measured cloud point, compared to the base diesel fuel. Also, there are numerous studies on oxygenate additives such as dimethyl ether, dimethyl carbonate. Menezes et al. [15] evaluated the effect of ether additives (ETBE and TAEE) in diesel and of ether/ethanol/diesel blends on the properties of density, volatility, viscosity, characteristics at cold temperatures, cetane number and performance in engine tests and they showed that the presence of ethanol and ETBE significantly altered the characteristics of volatility (flashpoint and distillation curve) and reduced the cetane number, impairing the fuel's performance in engine tests. Chen et al. [16] conducted a study of oxygenated biomass fuel blends on a diesel engine and they added the vegetable methyl ester into an ethanol-diesel fuel blend by increasing the ethanol proportion step by step and they concluded that the torque of the engine was decreased by $6 \%-7 \%$ for every $10 \%$ (by vol.) ethanol added to the diesel fuel without modification on the engine. Brake specific fuel consumption (BSFC) increased with the addition of oxygen from ethanol but equivalent brake specific fuel consumption (EBSFC) of oxygenated fuels was at the same level of that of diesel. Smoke and particulate matter (PM) emissions decreased significantly with the increase of oxygen content in the fuel. 
Lin and Wang [17] conducted a research on effects of an oxygenated additive on the emulsification characteristics of two- and threephase diesel emulsions. The results demonstrated that the viscosities of oil-in-water $(\mathrm{O} / \mathrm{W})$ and water-in-oil (W/O) two-phase emulsions increase with the increase of their inner phase content and the addition of an oxygenated agent. The addition of diglyme agent to the emulsions deteriorates the emulsification activity (EA) and emulsification stability (ES) of W/O and oil-in-water-in-oil (O/W/O). Zakharckhuk and Tkachuk [18] put forward a new technology on production and performance properties of isopropyl ester of rapeseed oil and they concluded that the synthesized biofuel was of a high quality and can be used in diesel engines.

On the other hand, effects of variation of compression ratio especially in diesel engines have also attracted great interest of researchers. Muralidharan and Vasudevan [19] studied on the influence of $\mathrm{CR}$ on the performance of a VCR engine running with waste cooking oil and its diesel blends fueled VCR engine to determine effects of $\mathrm{CR}$ variation on performance and they concluded that B40 blend depicted better performance in comparison to standard diesel at CR 21. Hirkude and Padalkar [20] made an investigation on the relationship between BSFC and exhaust gas temperature (EGT) with the increase of CR for waste fried oil methyl ester blend operated diesel engine. Bora and Saha [21] conducted an experimental analysis on influence of $\mathrm{CR}$ variation on performance and emissions of rice bran biodiesel-biogas dual fueled VCR diesel engine under 3 different CRs. They concluded that, in general, increment of $\mathrm{CR}$ drastically effects performance and emission characteristics.

In this study, due to its substantial high hydrogen and oxygen contents, EDTA was chosen as additive for sunflower methyl ester (B100). The classic structural formula of EDTA is $\mathrm{C}_{10} \mathrm{H}_{16} \mathrm{~N}_{2} \mathrm{O}_{8}$. EDTA is synthesized from ethylene diamine, formaldehyde and a source of cyanide ( $\mathrm{HCN}$ or $\mathrm{NaCN})$. EDTA is a novel molecule for complexion of metal ions. It is polyprotic acid containing four carboxylic acid and two amine groups with lone pair electrons [22]. Wear resistive additives place a high priority for fuels to prevent rapid engine failures. Carboxylic acids and their derivatives (esters and amides) are mostly suggested additives due to their wear resisting (preventing) specifications [23]. EDTA is only reactive with metal ions in solution, so it is not reactive with fuel injection system (fuel pump, fuel rails, injectors, gaskets, pistons, cylinder heads, etc.) materials which are in compound forms. Thereby, positive effects of EDTA on combustion were utilized without forming any damage on fuel injection system. Chemical structure of EDTA is depicted in Figure 1.

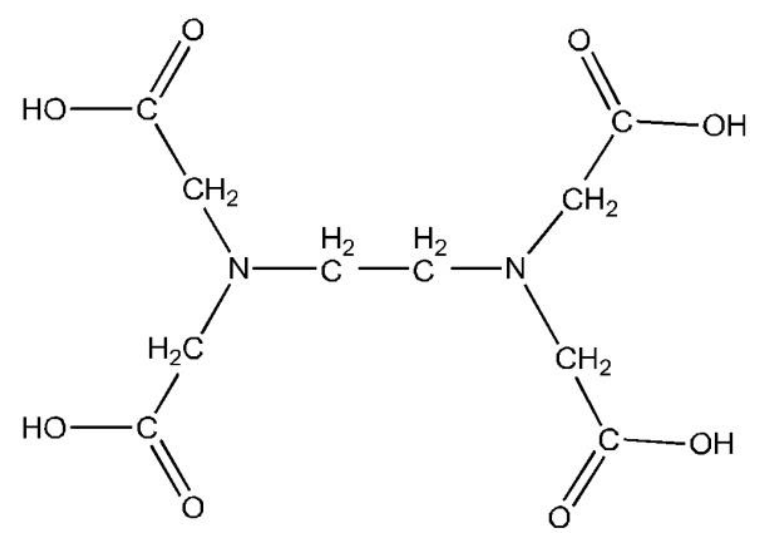

Figure 1. Chemical structure of EDTA

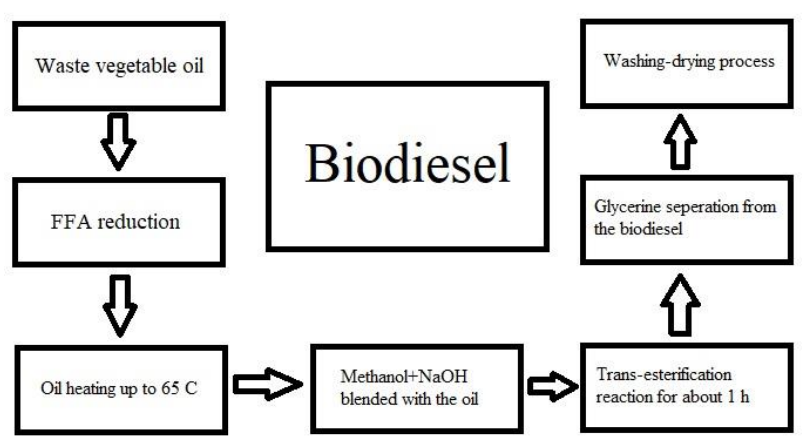

Figure 2. Biodiesel production process

\section{Experimental Techniques \\ and Specifications}

\subsection{Trans-esterification process}

Sunflower biodiesel (B100) was produced by trans-esterification of sunflower oil with $20 \%$ (by vol.) methanol in the presence of ratio of $5 / 1000$ (by wt.) $\mathrm{NaOH}$ catalyst. In the first step, waste sunflower oil underwent FFA reduction process (under 1\%) to enhance its biodiesel conversion efficiency. Then, the oil was heated up to $60-65^{\circ} \mathrm{C}$ on a heater and methanol- $\mathrm{NaOH}$ solution was poured into it to conduct transesterification reaction at about $60^{\circ} \mathrm{C}$ for 1 hour on condition that methanol was condensed during the reaction by a cooling tower. After the reaction, the sample was taken into a separation 
flask for separation of glycerin from the biodiesel. Subsequently, the washing and drying (at about $105^{\circ} \mathrm{C}$ ) processes of biodiesel were carried out and the neat biodiesel was achieved. Production steps of biodiesel and schematic of trans-esterification reaction are exhibited in Figure 2 and Figure 3, respectively.

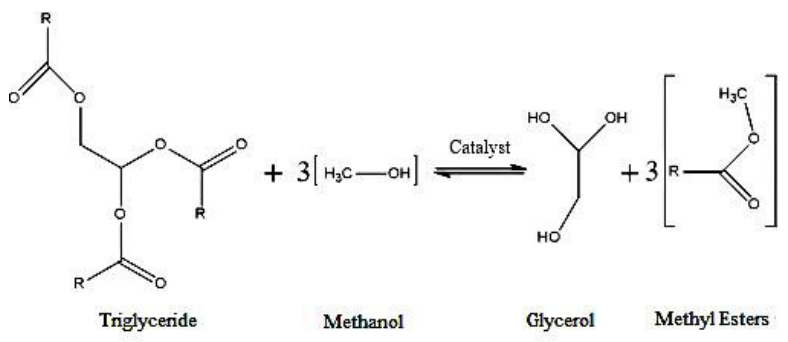

Figure 3. Demonstration of trans-esterification reaction

\subsection{Selection of EDTA as biodiesel additive}

Investigations were made on several features of chemicals to select an appropriate additive for B100 viz. reaction activity with metal and alloys (reactivity with fuel injection system material), miscibility in B100 ambient, chemical content for suitability as a fuel additive (specially oxygen and hydrogen contents) as well as considering the cost. EDTA depicted very small corrosion activity (negligible) with metals and alloys due to its chemical structure. In order to observe solubility, EDTA was added into B100 by weight ratios of $0.002 \%, 0.005 \%, 0.010 \%$, $0.015 \%, 0.017 \%, 0.019 \%$ and $0.020 \%$. The blends were mixed with an ultrasonic mixer and kept under room temperature for 3 weeks. It was concluded that, above ratio of $0.015 \%$ (by wt.), EDTA showed insolubility.

\subsection{Fuel properties determination procedure}

The devices used to determine the fuel properties are shown in Table 1.

Cetane Number $(\mathrm{CN})$, an important parameter for biodiesel quality, is a dimensionless indicator related to the ignition characteristics of a fuel in a cylinder, and can impact the engine's startability, noise level, and exhaust emissions. Better combustion achieved as a result of less ignition delay time or higher cetane number [24, 25].

Table 1. Fuel properties and measurement devices

\begin{tabular}{llcc}
\hline \multicolumn{1}{c}{ Property } & \multicolumn{1}{c}{ Device } & Accuracy & Measuring Range \\
\hline Cetane Number & Zeltex ZX440 & $3 \%$ & - \\
Lower Heating Value (LHV) & IKA-Werke C2000 Bomb Calorimeter & $0.001 \mathrm{~K}$ & - \\
Density & Kyoto Electronics DA-130 & \pm 0.001 & - \\
Viscosity & Saybolt Universal Viscosimeter & - & Ambient temp. to $240{ }^{\circ} \mathrm{C}$ \\
Flash Point & Tanaka Automated Pensky-Martens & - & Ambient temp. to $370{ }^{\circ} \mathrm{C}$ \\
& Closed Cup Flash Point Tester APM-7 & & $+51^{\circ} \mathrm{C}$ to $-40^{\circ} \mathrm{C}$ with \\
Pour Point & Tanaka MPC-102 water of $20^{\circ} \mathrm{C}$ and \\
& & - & $+51^{\circ} \mathrm{C}$ to $-65^{\circ} \mathrm{C}$ with \\
& & & cooling liquid of $-35^{\circ} \mathrm{C}$. \\
\hline
\end{tabular}

Density, viscosity, cold-flow properties, lower heating value (LHV), flash point compose other measurements of fuel quality in diesel engines. Viscosity, a measure of resistance to flow of a liquid due to the internal fluid friction [26] and is an important property because of its direct relation with the fuel injection process in engines [27, 28]. Biodiesel viscosity is usually higher than that of diesel, which results in longer liquid penetration and worse atomization compared to diesel fuel [29 - 32]. Flash point (FP) is the lowest temperature at which a liquid can form an ignitable mixture in air near its surface, where its measurement requires an ignition source. As FP of a volatile material is the lowest temperature at which vapors of a fluid will ignite, liquids with lower FP can be ignited easier [33]. The quantity known as lower heating value (LHV) (net calorific value (NCV) or lower calorific value (LCV)) is determined by subtracting the heat of vaporization of the water vapor from the higher heating value. This treats any $\mathrm{H}_{2} \mathrm{O}$ formed as a vapor. The energy required to vaporize the water therefore is not released as heat [34]. Engine performance and emission values substantially depend on LHV of fuels. Low temperature properties are characterized as the ability of a fuel to resist solidification at subambient temperatures. The low temperature properties are usually determined by pour point (PP) [35]. Fuel properties of B100 and B100+EDTA are shown in Table 2. 
Table 2. Fuel properties of B100 and B100+EDTA

\begin{tabular}{lccc}
\hline \multicolumn{1}{c}{ Properties } & B100 & B100+EDTA & European Biodiesel Standard (EN 14214) \\
\hline Density, $\mathrm{kg} / \mathrm{m}^{3}$ & 885 & 878 & $860-900$ \\
Cetane Number & 44.98 & 62.48 & Min 51 \\
& & & Summer $<4.0$ \\
Pour Point, ${ }^{\circ} \mathrm{C}$ & -7 & -6 & Winter $<1.0$ \\
Lower heating value, $\mathrm{MJ} / \mathrm{kg}$ & 35.71 & 37.43 & - \\
Flash point, ${ }^{\circ} \mathrm{C}$ & 148,5 & $>170$ & $>120$ \\
Kinematic viscosity, $\mathrm{mm}^{2} / \mathrm{s}$ & 4.23 & 3.91 & $3.5-5.0$ \\
\hline
\end{tabular}

\subsection{Engine performance and emission determination procedure}

Engine performance and emission experiments were conducted on a single cylinder, four stroke, water cooled, naturally aspirated, direct injection diesel engine. CR adjustment was conducted via a harmonic drive mechanism driven by an CR adjustment by tilting a "multilink" mechanism connected to the connecting rod and crankshaft. As the harmonic drive mechanism rotates in the clockwise direction, the $\mathrm{CR}$ of the engine decreases due to the downward movement of the piston or vice versa (Figure 4). There is an CR adjuster on the engine block which rotates the harmonic drive mechanism. When the adjuster is twisted in anticlockwise direction, the CR increases and the $\mathrm{CR}$ reading is taken from a scale carved onto the block. CR can also be changed while the engine is in operation. An eddy current type dynamometer with $185 \mathrm{~mm}$ arm length was used to load $(\mathrm{kg})$ the engine via electromagnetic forces. Technical specifications of the engine are given in Table 3. Schematic representation of diesel engine test rig is shown in Figure 5.

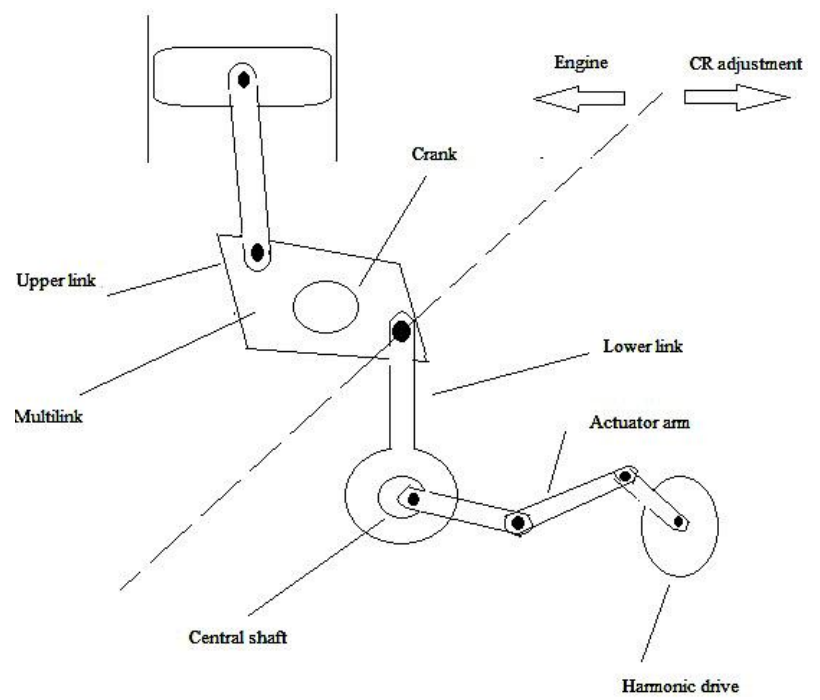

Figure 4. CR adjustment mechanism

TESTO $350 \mathrm{XL}$ gas analyzer was used to measure exhaust emissions. Emission data were collected via a computer program. Accuracy values of the gas analyzer are $\pm 10 \mathrm{ppm}$ for $\mathrm{CO}$, $\pm 1 \mathrm{ppm}$ for $\mathrm{NO}_{\mathrm{x}}, \pm 0.5 \%$ vol. for $\mathrm{CO}_{2}, \pm 10 \%$ for UHC. Smoke emissions were analyzed by a model 6500 Wager Digital Smoke meter of which accuracy is + OR - $1.0 \%$ nominal one digit. The control unit is initially calibrated under clear stack conditions with checks at $0 \%$ and $100 \%$ opacity. The accuracy of the unit is verified by use of the 2 neutral density filter supplied with the system.

Table 3. Technical specifications of the test engine

\begin{tabular}{ll}
\hline \multicolumn{1}{c}{ Specifications } & \multicolumn{1}{c}{ Descriptions } \\
\hline Configuration & Single cylinder \\
Type & Direct injection diesel \\
Displacement & $661 \mathrm{cc}$ \\
Bore & $87.5 \mathrm{~mm}$ \\
Stroke & $110 \mathrm{~mm}$ \\
Injection variation & $0-25^{\circ} \mathrm{BTDC}$ \\
CR range & $12: 1-18: 1$ \\
Power & $4.8 \mathrm{HP} \mathrm{@} 1500 \mathrm{rpm}$ \\
Coolant & Water \\
Aspiration &
\end{tabular}

Figure 5. Schematic representation of the engine test rig

Following equations were utilized in order to conduct performance analyses [36, 37]:

$$
B P=\frac{2 * \pi * N * \mathrm{~L} * \mathrm{~W}}{60} * 10^{-3}
$$

BP: Brake power $(\mathrm{kW})$; N: engine speed (rpm); $\mathrm{L}$ : dyno arm radius $(\mathrm{m})$; $\mathrm{W}$ : dyno load $(\mathrm{N})$

$$
\eta_{t}=\frac{36 * B P}{L H V_{f} * \dot{m}_{f}} * 10^{4}
$$

where; 
$\eta_{t}$ : Brake thermal efficiency (\%); LHVf: Lower heating value of the fuel $(\mathrm{MJ} / \mathrm{kg})$; mf: mass flow rate of the fuel $(\mathrm{kg} / \mathrm{h})$. BSEC may be computed as shown below:

$$
B S E C=\frac{\sum L H V_{f} * \dot{m}_{f}}{B P}
$$

\subsubsection{Uncertainty analysis}

Perturbation techniques were utilized to conduct uncertainty analysis [38] of performance and parameters ( $\eta_{t}$ and BSEC). $\eta_{t}$ errors were $1.7 \%$ and $3.1 \%$; BSEC errors were $1.6 \%$ and $3.1 \%$ for B100 and B100+EDTA, respectively. Relative errors of variables are shown in Table 4.

Table 4. Relative errors of variables

\begin{tabular}{lc}
\hline \multicolumn{1}{c}{ Variable } & Relative error \\
\hline Load & $0.6 \%$ \\
Speed & $0.6 \%$ \\
Fuel flow rate & $1.2 \%$ \\
LHV & $1 \%$ \\
CO, CO2, UHC, NOx, Smoke & $3.2 \%$ \\
\hline
\end{tabular}

\subsubsection{Brake thermal efficiency $\left(\eta_{t}\right.$}

Variations of $\eta_{t}$ with respect to engine load for B100 and B100+EDTA are indicated in Figure 6 . For both fuel modes, $\eta_{t}$ values were prone to increase as load and CR were elevated. Among fuel modes, B100+EDTA depicted higher average $\eta_{t}$ values of $24.3 \%, 26.3 \%$ and $27.8 \%$ whereas they were $18.3 \%, 19.4 \%$ and $20.3 \%$ for B100 under CRs of 16,17 and 18, respectively at IT of $22^{\circ}$ BTDC. As CR increases, augmented in-cylinder temperature and pressure yield fuels to undergo more complete combustion which leads to higher $\eta_{t}$ values for both fuel modes. Besides, B100+EDTA depicted superior performance in comparison to that of B 100 due to its higher heating value and cetane number.

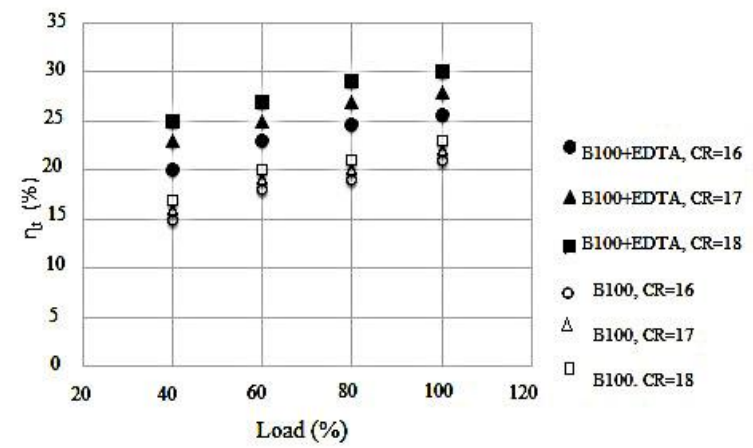

Figure 6. $\eta_{t}$-load variation for both fuel modes under variable conditions

\subsubsection{Brake specific energy consumption (BSEC)}

Variations of BSEC with respect to engine load for B100 and B100+EDTA are shown in Figure 7. In general, BSEC values were found to diminish with the increase of load under various CRs for both fuel modes. In terms of BSEC, average B100 values were 18.8, 16.8, 15.3 $(\mathrm{kJ} / \mathrm{kWs})$ whereas they were $10.1,9.5,8.4$ (kJ/kWs) for B100+EDTA under CRs of 16, 17 and 18, respectively. Increment in CR leads to higher in-cylinder temperature and pressures which shorten ignition delay time and yield rapid flame propagation. Under these conditions, lesser fuel injection is sufficient to achieve the same performance parameters compared to lower $\mathrm{CR}$ values which entails lower fuel consumption. Lower BSEC under B100+EDTA mode may be due to extra oxygen and hydrogen contents which may bring about shortened ignition delay, rapid and more complete combustion compared to that of B100.

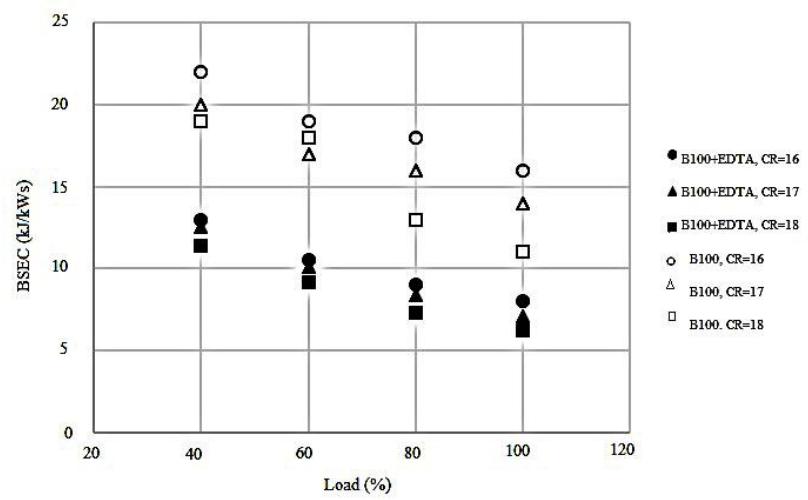

Figure 7. BSEC-load variation for both fuel modes under variable conditions

\subsubsection{Exhaust gas temperature $\left(T_{e}\right)$}

Variations of $T_{e}$ with respect to engine load for B100 and B100+EDTA are demonstrated in Figure 8. As the load increases, engine performs higher $\eta_{t}$ values which also cause increased $\mathrm{T}_{\mathrm{e}}$ values for both fuel modes under all CRs. It was found that, $T_{e}$ results were inversely proportional to $C R$ values. Average $T_{e}$ values were $227.2^{\circ} \mathrm{C}, \quad 201.8^{\circ} \mathrm{C}$ and $176.7^{\circ} \mathrm{C}$ for $\mathrm{B} 100+$ EDTA and $289.3^{\circ} \mathrm{C}, 278.4^{\circ} \mathrm{C}$ and $260.6^{\circ} \mathrm{C}$ for $\mathrm{B} 100$ at CRs of 16,17 and 18 , respectively. This may be due to lower calorific value and $\mathrm{CN}$ of $\mathrm{B} 100$ which cause longer ignition delay and late combustion initiation that lead to shorter power generation duration compared to B100+EDTA. CR adjustment from 
16 to 18 also yields more mixture take part in combustion process which caters lower exhaust gases and exhaust gas temperatures.

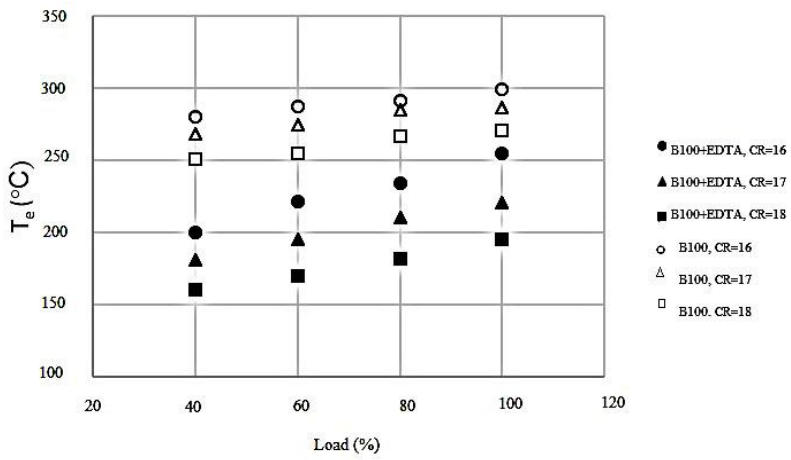

Figure 8. $\mathrm{T}_{\mathrm{e}}$-load variation for both fuel modes under variable conditions

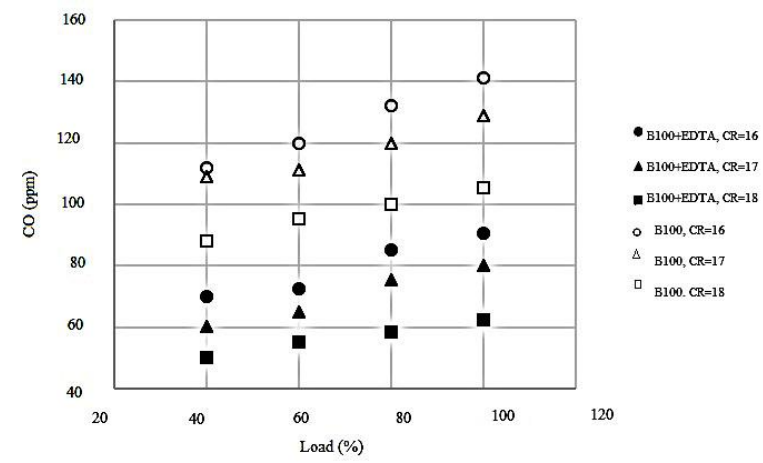

Figure 9. CO-load variation for both fuel modes under variable conditions

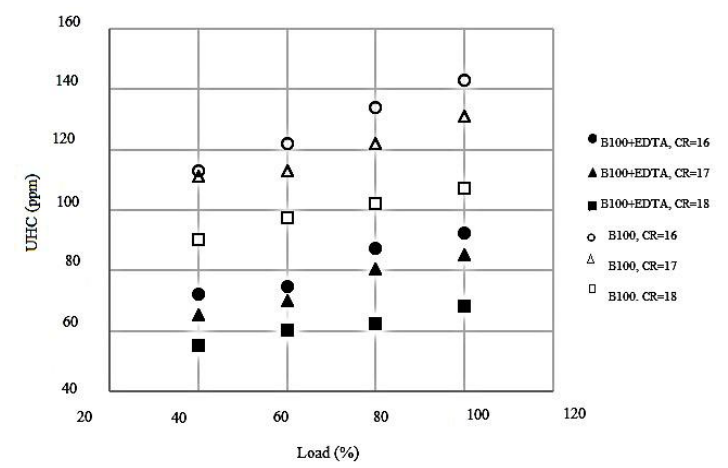

Figure 10. UHC-load variation for both fuel modes under variable conditions

\subsubsection{Carbon monoxide (CO) \& unburned hydrocarbon (UHC) emissions}

Variations of $\mathrm{CO}$ and $\mathrm{UHC}$ emissions with respect to engine load for B100 and B100+EDTA are exhibited in Figures 9 and 10, respectively. Formation of $\mathrm{CO}$ and $\mathrm{UHC}$ emissions substantially depend on in-cylinder combustion quality. Injection amount of fuel increases with the increase of load which stimulates rich mixture formation (insufficient air), partial combustion and consequently higher $\mathrm{CO}$ and UHC emissions especially at high loads for both fuel modes. Average $\mathrm{CO}$ values were 125, 117 and 97 (ppm) for B100; 79, 70 and 59 (ppm) for B100+EDTA under CRs of 16, 17 and 18 , respectively. UHC values of 128,119 and 99 (ppm) for B100; 82, 75 and 62 (ppm) for B100+EDTA were obtained under CRs of 16, 17 and 18, respectively. High CN and LHV of B100+EDTA ensure improved flame propagation and in-cylinder temperature to rise rapidly and more complete combustion with comparison to that of B100.

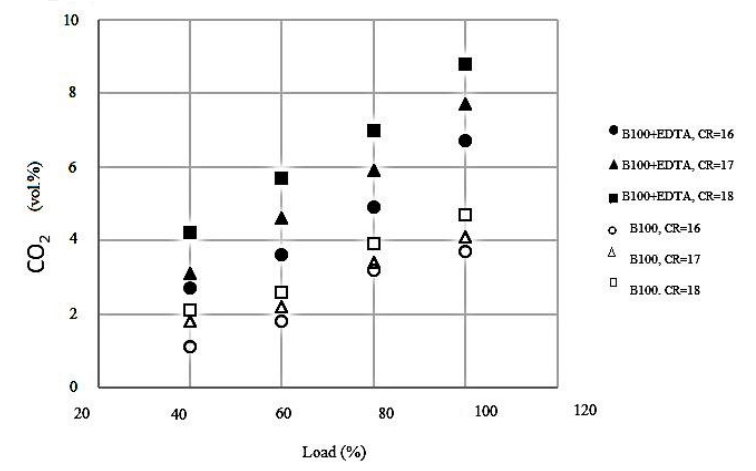

Figure 11. $\mathrm{CO}_{2}$-load variation for both fuel modes under variable conditions

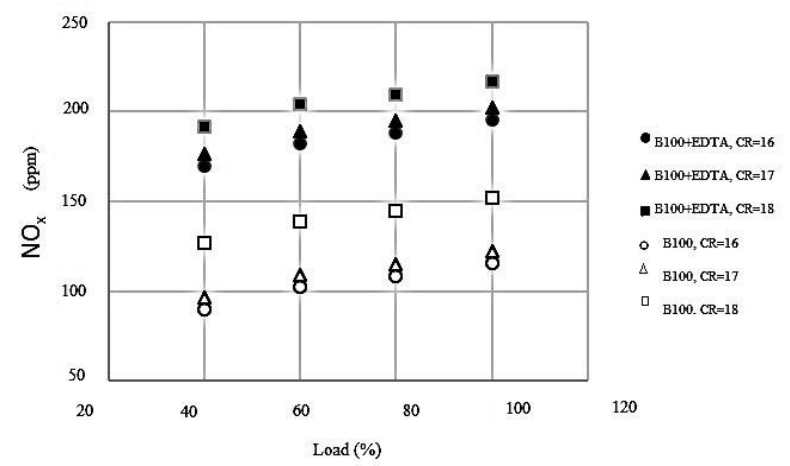

Figure 12. $\mathrm{NO}_{\mathrm{x}}$-load variation for both fuel modes under variable conditions

\subsubsection{Carbon dioxide $\left(\mathrm{CO}_{2}\right)$ \& nitrogen oxides $\left(\mathrm{NO}_{\mathrm{x}}\right)$ emissions}

Variations of $\mathrm{CO}_{2}$ and $\mathrm{NO}_{\mathrm{x}}$ emissions with respect to engine load for $\mathrm{B} 100$ and B100+EDTA are exhibited in Figures 11 and 12. In general, these emissions are consequences of end-combustion temperature and better combustion quality. For both fuel modes, fuel consumption increases with the increase in load which then induces augmented $\mathrm{CO}_{2}$. Average $\mathrm{CO}_{2}$ emission values are $4.3 \%, 5.7 \%$ and $6.3 \%$ (by vol.) for B100+EDTA; $2.4 \%, 2.8 \%$ and $3.3 \%$ for B100 under CRs of 16, 17 and 18, respectively. Higher calorific value and $\mathrm{CN}$ of B100+EDTA compared to that of B100 entail better combustion which yield more $\mathrm{CO}$ to be converted to $\mathrm{CO}_{2}$. Same interpretations may 
also be made for $\mathrm{CR}$ increment. $\mathrm{NO}_{\mathrm{x}}$ emissions also depict similar trend with those of $\mathrm{CO}_{2}$. As the load and CR increase, combustion temperature also increases due to high fuel injection quantities and in-cylinder temperature. Because $\mathrm{NO}_{\mathrm{x}}$ is largely dependent to endcombustion temperature, increment in $\mathrm{NO}_{\mathrm{x}}$ becomes inevitable. This interpretation may be made for CR increment as well. So, $\mathrm{NO}_{\mathrm{x}}$ values are found to be 184, 191 and 206 (ppm) for B100+EDTA; 104, 110 and 140 (ppm) for B100 under CRs of 16, 17 and 18, respectively.

\subsubsection{Soot formation}

Variations of exhaust smoke opacity (soot formation) with respect to engine load for B100 and B100+EDTA are shown in Figure 13. Particulate matters suspended in the exhaust gas ambient form soot due to inadequate oxygen (incomplete combustion) in the cylinder. Thus, higher fuel consumption at high loads causes more smoke to be formed and increased smoke opacity for both fuel modes. However, soot formation is prone to descend with the increase in CR. Higher CR means more suitable conditions for complete combustion due to high in-cylinder temperature and pressure. Average smoke opacity values were $15 \%, 12 \%$ and $10 \%$ for B100+EDTA; $19 \%, 17 \%$ and $16 \%$ for B100 under CRs of 16, 17 and 18, respectively. High oxygen, hydrogen content and superior LHV and $\mathrm{CN}$ of B100+EDTA stimulate more complete combustion and provide diminished soot formation.

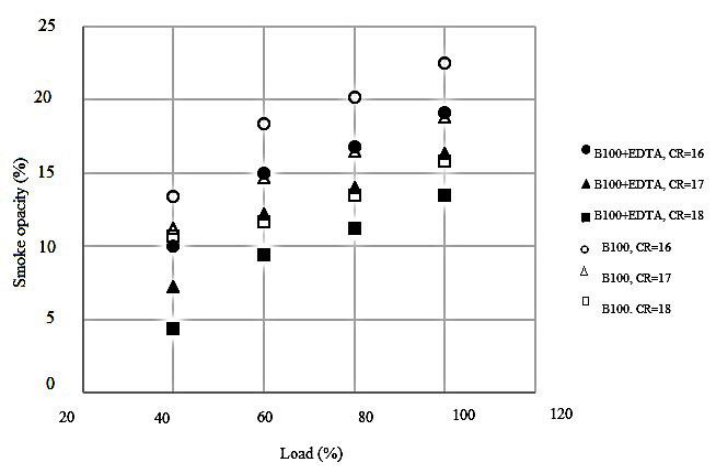

Figure 13. Smoke opacity-load variation for both fuel modes under variable conditions

\section{Cost Analysis}

Table 5 depicts the cost analysis of this study. The total cost of $5.03 \mathrm{~L}$ of biodiesel production from waste sun flower oil is $\$ 6.59$ which corresponds to $\$ 1.17 / \mathrm{L}$. Considering $\$ 1.11 / \mathrm{L}$ current unit price of diesel fuel in Turkey, it is clear that, in general, the cost of the sun flower methyl ester with EDTA is comparable with that of the diesel fuel.

Table 5. Cost analysis of the experimental study

\begin{tabular}{lccc}
\hline \multicolumn{1}{c}{ Substance } & Amount Used & Unit Price & Cost \\
\hline Waste sunflower oil & $4550 \mathrm{~g}$ & - & \\
EDTA & $0.0665 \mathrm{~g}$ & $\$ 25.19 / 100 \mathrm{~g}$ & $\$ 0.016$ \\
$\mathrm{NaOH}$ & $22.8 \mathrm{~g}$ & $\$ 21.35 / 500 \mathrm{~g}$ & $\$ 0.97$ \\
Methanol & $1.03 \mathrm{~L}$ & $\$ 4.77 / 1 \mathrm{~L}$ & $\$ 4.91$ \\
TOTAL & & & $\$ 6.59$ \\
\hline
\end{tabular}

\section{Conclusions}

In this experimental study, effect of EDTA addition into B100 on performance and emissions of a diesel engine under variable loads and CR conditions was evaluated. In general, improved performance characteristics, diminished $\mathrm{CO}$, UHC, soot formation and increased $\mathrm{CO}_{2}$ and $\mathrm{NO}_{\mathrm{x}}$ emissions were determined with the increase in CR from 16 to 18 at the IT of $22^{\circ}$ BTDC for both fuel modes. Moreover, EDTA addition into B100 provided better results in terms of performance, exhaust gas temperature, BSEC, $\mathrm{CO}$, UHC and soot formation except for $\mathrm{NO}_{\mathrm{x}}$ and $\mathrm{CO}_{2}$ as the $\mathrm{CR}$ increases due to its high oxygen, hydrogen content, LHV and $\mathrm{CN}$ values. Among fuel modes, B100+EDTA with CR of 18 provided the highest brake thermal efficiency, $\mathrm{CO}_{2}$ and $\mathrm{NO}_{\mathrm{x}}$ emission values due to improved combustion characteristics which also led to the lowest BSEC values. Furthermore, this study depicts that EDTA can be used as an appropriate additive for biodiesel fuels in terms of its low cost and positive effect on performance and emissions except $\mathrm{CO}_{2}$ and $\mathrm{NO}_{x}$, especially under high $\mathrm{CR}$ values.

\section{Acknowledgment}

The author would like to thank Cukurova University, Department of Automotive Engineering, Fuel Analysis Laboratories and Marmara University Laboratories. 


\section{Nomenclature}

$\eta_{t} \quad$ : Brake thermal efficiency $(\%)$

BP : Brake power $(\mathrm{kW})$

$\mathrm{N} \quad$ : Engine speed (rpm)

$\mathrm{L} \quad$ : Dyno arm radius (m)

W : Dyno load (N)

LHW : Lower heating value $(\mathrm{MJ} / \mathrm{kg})$

$\mathrm{m}_{\mathrm{f}} \quad$ : Mass flow rate $(\mathrm{kg} / \mathrm{h})$

BSEC : Brake specific energy consumption $(\mathrm{MJ} / \mathrm{kWh})$

\section{References}

1. Ali, Y., \& Hanna, M.A. "Alternative diesel fuels from vegetable oils", Bioresource Technology, 50(2), 153-63, 1994.

2. Balat, M., \& Balat, H. "Progress in biodiesel processing", Appl Energy, 87(6), 1815-1835, 2010.

3. Beck, A., Pölczmann, G., Eller, Z., \& Hancsók, J. "Investigation of the effect of detergent-dispersant additives on the oxidation stability of biodiesel, diesel fuel and their blends", Biomass and Bioenergy, 66, 328-336, 2014.

4. Bora, B.J., Saha, U.K., Chatterjee, S., \& Veer, V. "Effect of compression ratio on performance, combustion and emission characteristics of a dual fuel diesel engine run on raw biogas", Energy Convers. Manag., 87, 2014.

5. Bora, B.J., \& Saha, U.K. "Experimental evaluation of a rice bran biodiesel biogas run dual fuel diesel engine at varying compression ratios", Renewable Energy, 87(1), 782-790, 2015.

6. Bora, B.J., \& Saha, U.K. "Comparative assessment of a biogas run dual fuel diesel engine with rice bran oil methyl ester, pongamia oil methyl ester and palm oil methyl ester as pilot fuels", Renew. Energy, 81, 490-498, 2015. 7. Caynak, S., Guru, M., Bicer, A., Keskin, A., \& Icingur, Y. "Biodiesel production from pomace oil and improvement of its properties with synthetic manganese additive", Fuel, 88(3), 534-538, 2009.

8. Chen, H., Wang, J., Shuai, S., \& Chen, W. "Study of oxygenated biomass fuel blends on a diesel engine", Fuel, 87(15-16), 34623468, 2008.

9. Danilov, A.M. "Development and use of fuel additives during 2006-2010", Chemistry and Technology of Fuels and Oils, 47(6), 470484, 2012.

10. Demirbas, A. "Biomass resource facilities and biomass conversion processing for fuels and chemicals", Energy Conversion Management, 42(11), 1357-1378, 2001.

11. Demirbas, A. "Importance of biodiesel as transportation fuel", Energy Policy, 35(9). 4661-4670, 2007.

12. Franco, Z., \& Nguyen, Q.D. "Flow properties of vegetable oil-diesel fuel blends", Fuel, 90(2), 838-843, 2011.

13. Gerhartz, W., Yamamoto, Y.S., Kaudy, L., Rounsaville, J.F., \& Schulz G. 'Ullmann's Encyclopedia of Industrial Chemistry, $5^{\text {th }}$ ed., Weinheim, Germany, 2000.

14. Goodrum, J.W., \& Law, S.E. "Rheological properties of peanut oil-diesel fuel blends", Transactions of the American Society of Agricultural and Biological Engineers, 25(4),897-900, 1982.

15. Hirkude, J., \& Padalkar, A.S. "Experimental investigation of the effect of compression ratio on performance and emissions of CI engine operated with waste fried methyl ester blend", Fuel Process. Technol., 128, 367-375, 2014.

16. Hoekman, S.K., Broch, A., Robbins, C., Ceniceros, E., \& Natarajan, M. "Review of biodiesel composition, properties, and specifications", Renew. Sustain. Energy Rev., 16, 143-169, 2012.

17. https://en.wikipedia.org/wiki/Heat_of_c ombustion\#Lower_heating_value, 16/05/2016.

18. Ileri, E., \& Kocar, G. "Experimental investigation of the effect of antioxidant additives on $\mathrm{NO}_{\mathrm{x}}$ emissions of a diesel engine using biodiesel", Fuel, 125, 44-49, 2014.

19. Imtenan, S., Masjuki, H.H., Varman, M., Kalam, M.A., Arbab, M.I., Sajjad, H., \& Rahman, S.M.A. "Impact of oxygenated additives to palm and jatropha biodiesel blends in the context of performance and emissions characteristics of a light-duty diesel engine", Energy Conversion and Management, 83, 149158, 2014.

20. Karavalakis, G., Stournas, S., \& Karonis, D. "Evaluation of the oxidation stability of diesel/biodiesel blends", Fuel, 89(9), 2483-2489, 2010.

21. Keshavarz, M.H., Jafari, M., Kamalvand, M., Karami, A., Kerhavarz, Z., 
Zamani, A, \& Rajaee, S. "A simple and reliable method for prediction of flash point of alcohols based on their elemental composition and structural parameters", Proc. Safety and Env. Prot. 102, 1-8, 2016.

22. Knothe, G. et al. "The Biodiesel Handbook", American Oil Chemists Society Press, 2005.

23. Knothe, G., Krahl, J., \& Van Gerpen, J.H. "The biodiesel handbook", AOCS Press, 2010.

24. Lin, C., \& Wang, K. "Effects of an oxygenated additive on the emulsification characteristics of two- and three-phase diesel emulsions", Fuel, 83(4-5), 507-515, 2004.

25. Lin, B.F., Huang, J.H., \& Huang, D.Y. "Experimental study of the effects of vegetable oil methyl ester on DI diesel engine performance characteristics and pollutant emissions", Fuel, 88, 1779-1785, 2009.

26. Liu, H., Jiang, S., Guo, H., Han, S., Yang, C., \& Jiang, J. "A new kind of pour point depressant: Diesel from direct coallique faction", Fuel Proc. Tech., 149, 285-289, 2016. 27. Menezes, E.W., Silva, R., Cataluna, R., \& Ortega, R.J.C. "Effect of ethers and ether/ethanol additives on the physicochemical properties of diesel fuel and on engine tests", Fuel, 85(5-6), 815-822, 2006.

28. Meng, X., Jia, M., \& Wang, T. "Predicting biodiesel densities over a wide temperature range up to $523 \mathrm{~K}$ ", Fuel, 111, 216222, 2013.

29. Meng, X., Jia, M., \& Wang, T. "Neural network prediction of biodiesel kinematic viscosity at 313 K'. Fuel, 121, 133-140, 2014.

30. Miraboutalebi, S.M.R., Kazemi, P., \& Bahrami, P. "Fatty Acid Methyl Ester (FAME) composition used for estimation of biodiesel cetane number employing random forest and artificial neural networks: A new approach", Fuel, 166, 143-151, 2016.

31. Moffat, R. J. ASME J. Fluids Eng., 104, 250-264, 1982.

32. Muralidharan, K., \& Vasudevan, D. "Performance, emission and combustion characteristics of a variable compression ratio engine using methyl esters of waste cooking oil and diesel blends", Appl. Energy, 88, 39593968, 2011.

33. Reijnders, L. "Conditions for the sustainability of biomass based fuel use",
Energy Policy, 34(7), 863-76, 2006.

34. Poling, B.E., Prausnitz, J.M., \& O'Connell, J.P. "The properties of gases and liquids", McGraw-Hill, New York, 2001.

35. Sensoz, S., Angin, D., \& Yorgun, S. "Influence of particle size on the pyrolysis of rapeseed (Brassicanapus L.): fuel properties of bio-oil", Biomass Bioenergy, 19(4), 271-279, 2000.

36. Tracy, N.I., Chen, D., Crunkleton, D.W., \& Price, G.L. "Hydrogenated monoterpenes as diesel fuel additives", Fuel, 88(11), 2238-2240, 2009.

37. Yuan, W., Hansen, A.C., \& Zhang, Q. "Predicting the temperature dependent viscosity of biodiesel fuels", Fuel, 88, 1120-1126, 2009. 38. Zakharchuk, V.I., \& Tkachuk, V.V. "Technology of production and performance properties of isopropyl ester of rapeseed oil", Chemistry and Technology of Fuels and Oils, 48(6), 421-425, 2013. 